\title{
La santidad en la Biblia
}

\author{
Agustín Giménez González \\ Universidad Eclesiástica San Dámaso (Madrid) ${ }^{1}$
}

\begin{abstract}
Resumen: El presente artículo tiene tres partes. La primera se centra en la santidad de Dios desde los textos bíblicos, siendo ésta fuente de toda otra santidad, la cual se manifiesta en su belleza, su verdad y su bondad. La segunda desarrolla la invitación divina al hombre de vivir esta santidad en el proyecto original de la creación, así como la pobre respuesta del ser humano. La tercera mira al futuro en el que Dios ha prometido llevar a cabo la santificación de los hombres.
\end{abstract}

Palabras claves: santidad, Biblia, pecado, ley, promesa.

\begin{abstract}
This paper has three parts. The first focuses on the holiness of God from the biblical texts, being this holiness the source of all other holiness, which is manifested in its beauty, its truth and its goodness. The second develops the divine invitation to man to live this holiness in the original project of creation, as well as the poor response of the human being. The third looks to the future in which God has promised to carry out the sanctification of men.
\end{abstract}

Keywords: holiness, Bible, sin, law, promise.

Es para mí una gran alegría publicar en la revista de esta Archidiócesis de Sevilla, porque en esta porción de la Iglesia santa de Dios se ama con una especialísima devoción a la Virgen María, como de todos es bien sabido. A Ella encomiendo el fruto de este artículo, y le pido siga conservando en el corazón de todos los sevillanos un filial y profundo afecto mariano.

El tema que voy a abordar es hermoso, es importante, y es apasionante: la santidad en la Biblia. Lo desarrollaré en tres puntos:

Fecha de recepción: 20 de abril de 2019

Fecha de aceptación y versión final: 4 de mayo de 2019

1 Este trabajo ha sido realizado con la ayuda financiera del Centro Español de Estudios Eclesiásticos anejo a la Iglesia Nacional Española de Santiago y Montserrat en Roma en el marco de los proyectos de investigación del curso 2018-2019. 
1. Dios es el Santo por antonomasia, es decir, el Santísimo.

2. La llamada a la santidad de la criatura.

3. La gran promesa.

\section{DIOS ES EL TRES VECES SANTO, EL SANTÍSIMO}

La Sagrada Escritura testimonio que solo hay un Santo: Dios. Solo a Él corresponde este adjetivo, hasta el punto de que la santidad emana de su ser. No hay santidad que no proceda de Dios. Esta santidad se hace patente de modo especial en las teofanías del Antiguo Testamento. Recordemos aquella paradigmática del profeta Isaías en el Templo de Jerusalén en el siglo viII a. C.:

“El año de la muerte del rey Uzías vi al Señor sentado en un trono excelso y elevado. El vuelo de su manto llenaba el Templo. Unos serafines se mantenían por encima de Él. Cada uno tenía seis alas: con dos se cubrían el rostro, con dos se cubrían los pies, y con dos volaban. Clamaban entre sí diciendo: - ¡Santo, Santo, Santo es el Señor de los ejércitos! ¡Llena está toda la tierra de su gloria! (Is 6,1-3)”. ${ }^{2}$

Los ángeles proclaman la infinita santidad de Dios por medio del triple

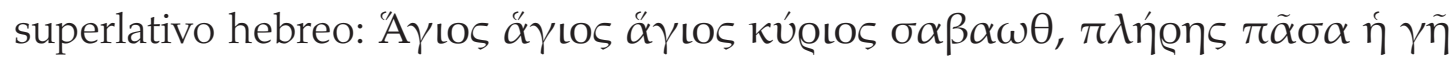

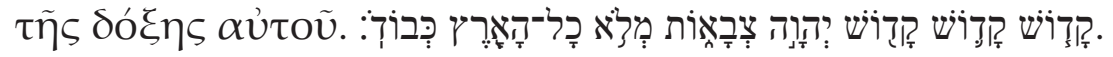

Tanto hagios en griego como kadosh en hebreo remiten a la santidad excelsa de Dios. Es un término que tanto en la Lxx como en la Tanak (biblia hebrea) se le atribuye principalmente a Dios, o a lo perteneciente al ámbito celestial, o a aquellos que han sido capacitados para acercarse a Él. ${ }^{3}$ De hecho, el griego, cuando quiere mencionar que un ser humano es santo en el sentido que empleamos en castellano, no emplea el adjetivo hagios, sino hosios (santo moralmente) o dikaios (justo, recto, intachable). Aunque hagios remite a la santidad propia de Dios, en Él también se dan en plenitud estos otros conceptos, la hosiotês y la dikaiosynê, de tal modo que Dios es el perfectamente hagios, hosios y dikaios.

¿Qué podemos decir, entonces, de la triple santidad de Dios? Fundamentalmente tres afirmaciones:

1. Como ya hemos señalado, hagios se refiere a la santidad sagrada, inalcanzable y majestuosa, de la esfera divina, y en este sentido remite a la gloria de Dios mencionada por los serafines de la teofanía de Isaías. Así, la santidad de Dios es su esplendor, su belleza, su majestad... aquello de Dios que

2 Cf. Gabriele Winkler, Das Sanctus: Über den Ursprung und die Anfänge des Sanctus und sein Fortwirken (Orientalia Christiana Analecta 267) Rome, Pontificio Istituto Orientale, 2002; Albert A. S. Ten Kate, "L'origine du Sanctus", Ephemerides Theologicae Lovanienses 83 (2007) 193-201; Emmanuel DurAnd, "God's Holiness. A reappraisal of transcendence", Modern Theology 34 (2018) 419-433.

3 Cf. Henry S. Gehman, "A $\gamma$ tos in the Septuagint, and its relation to the Hebrew original", Vetus Testamentum 4 (1954) 337-348. 
atrae, seduce y nos deja fascinados. Esta gloria de Dios ha quedado plasmada en la belleza de las criaturas, que reflejan tenuemente la majestad de su Creador.

2. Pero la santidad de Dios también incluye su omnipotencia. La majestad de su gloria se manifiesta en su poder absoluto sobre todo lo creado. Se trata de un poder no equiparable a ningún otro, sino sustentador de cualquier poder, pues es la potestad creadora (cf. Gén 1-2) y salvadora de Dios (cf. Éx 14-15, passim). En cuanto poder creador, su santidad otorga la verdad del ser a todas las cosas. En cuanto poder salvador, la santidad de Dios rescata a la criatura de la corrupción y la lleva a su verdad plena.

3. Ahora bien, lo más sobresaliente de la santidad de Dios, inseparable de su belleza, de su poder y de su verdad, es su infinita bondad y misericordia. ${ }^{4} \mathrm{Si}$ algo caracteriza al testimonio bíblico sobre Dios es que afirma que es bueno, buenísimo, ilimitadamente bueno, "porque es eterna su misericordia" (cf. Sal 117; 135).

Así pues, la santidad de Dios en la Biblia remite a los tres trascendentales del ser, la belleza, la verdad y el bien, los cuales no solo se dan en plenitud en Dios, sino que se identifican con su ser, y se manifiestan en su actuar. Su acción, a su vez, se despliega a través de su poder infinito.

Este poder, como señala el libro de la Sabiduría, es pleno porque su bondad es total. La omnipotencia de Dios es la base de su caridad sin límite: "te compadeces de todos, porque todo lo puedes y pasas por alto los pecados de los hombres para que se arrepientan. Amas a todos los seres y no aborreces nada de lo que hiciste; pues, si odiaras algo, no lo habrías creado [...] Tú eres indulgente con todas las cosas, porque son tuyas, Señor, amigo de la vida" (Sab 11,23-24.26). ${ }^{5}$

En efecto, Dios no solo es bueno, sino que además es el único realmente

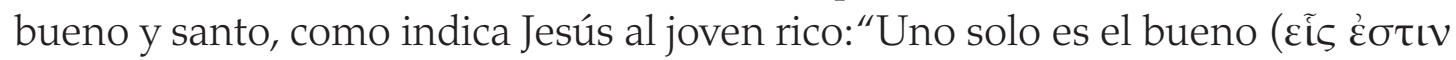
ó $\alpha \gamma \alpha \theta$ ós)" (Mt 19,17), ," no hay nadie bueno más que Dios; nadie es bueno sino

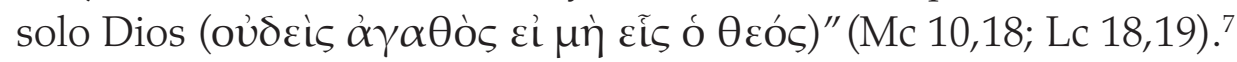

4 Cf. Maurice Gilbert, “Ĺamore di Dio per le creature”, en Maurice Gilbert (ed.), La sapienza di Salomone II (BeP 23), Roma, Apostolato della Preghiera, 1995, 83-92.

5 Cf. Agustín Giménez González, "El Dios filántropo de Sabiduría”, en Carmen Bernabé (ed.), Los rostros de Dios (ABE 62), Estella, Verbo Divino, 2013, 132-133; Maurice GILBERT, “Le ragioni della moderazione divina (Sap 11,21-12,2)", en Maurice GIlbert (ed.), La sapienza di Salomone I (BeP 22), Roma, Apostolato della Preghiera, 1995, 165-181.

6 Cf. Isidro Gomá Civit, El Evangelio según San Mateo II, Madrid, Marova, 1976, 259-260; Ulrich Luz, El Evangelio según San Mateo III. Mt 18-25 (BEB 111), Salamanca, Sígueme, 2003, 168-169.

7 Cf. Josef Schmid, El Evangelio según San Marcos (BH.SE 93), Barcelona, Herder, ${ }^{21973,}{ }^{1} 1967$, 275; Vincent TAYLOR, Evangelio según San Marcos (BBC), Madrid, Cristiandad, 1979, 508; François Bovon, El Evangelio según San Lucas III. Lc 15,1-19,27 (BEB 87), Salamanca, Sígueme, 2004, 291; Joseph A. FITZMYeR, El Evangelio según Lucas IV. Traducción y comentario. Capítulos 18,15-24,53 (CSE), Madrid, Cristiandad, 2005, 23. 
Esta bondad se pone de manifiesto en todas sus obras, la primera de las cuales es la creación del universo. Dios crea movido únicamente por su bondad, lo cual queda especialmente puesto de manifiesto al comparar los relatos bíblicos de la creación (Gén 1 y 2) con los respectivos relatos mesopotámicos, como el Enuma Elish o el Atrahasis. ${ }^{8}$ En estos textos, la tierra no es consecuencia de un acto de amor de Dios, como indicaba el libro de la Sabiduría, sino los despojos del dios malo, Tiamat, modelados por el dios Marduk. Por tanto, tiene en sus entrañas el germen del mal y la rebelión. Y el ser humano, a su vez, tampoco es creado por amor, sino por exigencia de los igigu, los dioses menores, que quieren que otros hagan su trabajo para poder ellos descansar eternamente. ${ }^{9}$

El testimonio bíblico, sin embargo, manifiesta que Dios crea sin necesidad de hacerlo, sin que esto le reporte ningún beneficio, en un acto libérrimo de su voluntad. Podría no haber creado nada, que no le faltaría nada ni a su majestad ni a su felicidad. Dicho con otras palabras, Dios crea por amor, movido libremente por su santidad.

Además, en todo lo que crea plasma su propia bondad, y asílo manifiesta Él mismo. Tras crear la luz, se dice:"vio Dios que la luz era buena" (Gén 1,4), y hasta siete veces se repite el mismo estribillo en este relato, que concluye así:"vio Dios todo lo que había hecho, y era muy bueno" (Gén 1,31). ${ }^{10}$ No podía ser de otro modo: de un ser infinitamente bueno y todopoderoso solo podían salir criaturas en sí mismas buenas, que participasen de la bondad de su Creador. Ahora bien, de entre todas ellas sobresale una, el ser humano, la única de la que se afirma que fue creada a su imagen y semejanza (Gn 1,26). ${ }^{11}$ Es decir, que en esta criatura Dios se ha empeñado especialmente para que se parezca a Él, para que sea como Él, buena y santa. Dios ha querido compartir con ella su ser, su perfección. A diferencia de los dioses griegos, por ejemplo, que como vemos en el mito de Prometeo no querían ni compartir el fuego - un don propio de los dioses del Olimpo- con los hombres, el Dios de la revelación bíblica quiere compartir todo lo que Él es con el ser humano. Tal es así que le ofrece su propia divinidad, como señala 2 Pe 1,3-4:"nos ha llamado con su propia gloria y potencia [..] para que seáis partícipes de la naturaleza divina". ${ }^{12}$

Esto significa que todo hombre viene a la existencia con una vocación, una llamada a ser como Dios. Esa es la razón de ser de haber sido creado a imagen de Dios: alcanzar la semejanza con Dios, como diría san Ireneo. Él distinguía el

8 Cf. Lluis Feliu Mateu - Adelina Millet AlbÀ (eds.), Enūma eliš. Y otros relatos babilónicos de la Creación (Pliegos de Oriente) Barcelona, Trotta, 2014, 21-24. 44-45.

9 Cf. Agustín Giménez GonzÁlez, Pentateuco y libros históricos (ISCCRR.D 1.7), Madrid, Universidad Eclesiástica San Dámaso, Madrid 2015, 34-35.

10 Cf. Gerhard von Rad, El libro del Génesis, Salamanca, Sígueme, ${ }^{2} 1982,72-73$.

11 Cf. Pierre Grelot, Hombre, ¿quién eres? Los once primeros capitulos del Génesis (CuaBib 5), Estella, Verbo Divino, 1976, 29-30.

12 Cf. Scott J. Hafemann, " «Divine nature» in 2 Pet 1,4 within its eschatological content", Bib 94 (2013) 80-99. 
ser imagen de Dios como un dato creatural de todo ser humano, y el ser semejante a Dios como nuestra vocación y finalidad, fruto de la acción del Espíritu Santo en el hombre. Así, ser imagen de Dios es la condición de posibilidad para llegar a ser semejante a Dios. El ser humano, a diferencia de las otras criaturas animales, tiene la capacidad de amar, al igual que Dios, lo que presupone a su vez el don de la libertad para elegir el bien, y el don de la inteligencia para conocer la verdad. Ahora bien, esa misma libertad, necesaria para poder amar y expresión de la bondad de Dios, pondrá en continuo peligro la vocación del hombre, pues podría igualmente ser usada para no amar. ${ }^{13}$

\section{EL HOMBRE, LLAMADO A LA SANTIDAD DE DIOS}

El único santo quiere que los seres humanos sean igualmente santos. Como señala San Pablo, este es el motivo de la creación: "Él nos eligió en Cristo antes

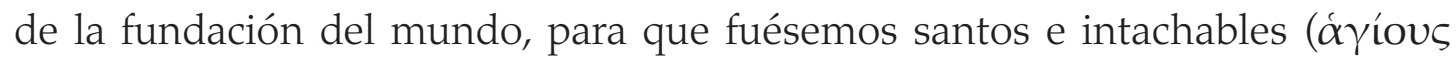

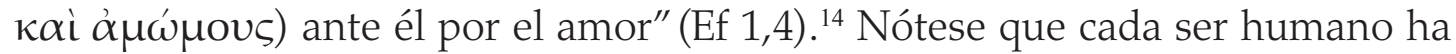
sido pensado, elegido y amado por Dios previamente a existir, desde antes de la creación del universo. El cosmos ha venido a ser en función de esta elección de Dios: nuestra santidad. No solo una santidad moral, o de justicia, sino la santidad majestuosa y gloriosa de Dios. Quiere que seamos hagioi, del mismo modo que Él es hagios.

Esto es posible, como indica el himno de Efesios, "por el amor" infinito que nos tiene. No porque nosotros alcancemos esa santidad por nosotros mismos, sino porque Él establece una relación de amor con el hombre y, en el trato amoroso de ambos (posible por ser el hombre imagen de Dios), el ser humano se santifica y diviniza. Este es el fin, el objetivo del plan salvífico: que Dios y su criatura vivan en comunión, para lo cual el hombre es invitado a una relación de amor, de unidad y de confianza con su Creador. Esto se manifiesta en los dos relatos de la creación del Génesis. En el primero, por la ya mencionada creación a imagen y semejanza (Gén 1,26-27).

En el segundo (cf. Gén 2), ${ }^{15}$ en cambio, se percibe en los continuos beneficios que Adán recibe por parte de Dios: ser modelado de la tierra por sus propias manos (cf. Gén 2,7a), insuflar de Dios su propio aliento de vida (cf. Gén 2,7b), un jardín con toda clase de árboles hermosos y apetitosos (cf. Gén 2,8), el libre acceso al árbol de la vida (cf. Gén 2,9), sabiduría divina para conocer cómo evitar el pecado y la muerte (cf. Gén 2,17), la ayuda y el gobierno de los animales

13 Por este motivo Henri de LUBAC considera que la libertad del hombre, mientras este camina por la tierra, está amenazada, pues sobre ella pesa la amenaza de no llegar a realizar el fin por el que ha sido dada, amar. Solo en la bienaventuranza del cielo nuestra libertad será plena y estará libre de toda amenaza, pues se empleará solo para amar.

14 Cf. Heinrich Schlier, La carta a los Efesios. Comentario (Biblioteca de Estudios Bíblicos 71), Salamanca, Sígueme, ${ }^{22006,62-67 . ~}$

15 Cf. Grelot, Hombre, iquién eres?, 23-25. 
(cf. Gén 2,18-20), y la maravillosa compañía de Eva (cf. Gén 2,21-25), que se une a las bendiciones del primer relato sobre la fecundidad humana y el dominio de la tierra (cf. Gén 1,28-30).

Tantos dones de Dios son expresión de su amor al hombre, del deseo divino de vivir en comunión con su criatura predilecta, la cual debía alcanzar su plenitud comiendo del árbol de la vida, evitando pecar (esto es, comer del árbol del conocimiento del bien y del mal) y llevando a cabo la misión de Dios. ¿Qué misión? La de" guardar"y“servir"el jardín paradisíaco. Como señala Scott Hahn, cuando estos dos verbos hebreos ('abad y 'samar) aparecen juntos en el Pentateuco, remiten a la actividad propia de los sacerdotes en el culto del Templo, que deben guardar y servir. ${ }^{16}$ Por tanto, todo ser humano tiene una vocación sacerdotal, de relacionarse con Dios como sacerdote, de entrar en relación con Dios, convirtiendo la tierra en un gran Templo donde habite la gloria de Dios para que el hombre participe de ella. Su vocación última es, por tanto, que la santidad de Dios inunde la tierra, siendo él el mediador sacerdotal a través de su comunión con la santidad divina. Así, todo el universo será un gran Templo que glorifique eternamente a Dios.

Ese anhelo que tiene Dios por convivir con el hombre se expresa, finalmente, en el hecho de que Dios baje al jardín a su encuentro, como si se tratase del sancta sanctorum, y le busque: Adán, “ ¿dónde estás?” (Gén 3,9).

Ahora bien, como todos sabemos, desde el inicio el hombre traicionó su vocación a la santidad. Como señala Sab 2,23, releyendo Gén 3, “Dios creó al hombre incorruptible y lo hizo a imagen de su propio ser; mas por envidia del diablo entró la muerte en el mundo" ${ }^{17}$ Este ángel caído, representado por la serpiente en Gén 3,1-5, logró lo que parecía imposible: convencer al ser humano de que Dios no era bueno ni santo, sino su enemigo, el rival de su felicidad, el obstáculo que le impedía alcanzar la plenitud. He aquí la raíz del pecado: dudar de la bondad de Dios, poner en tela de juicio su santidad. Nótese que no hay ningún pensamiento más perverso ni irracional que este. Dios, que se ha deshecho en beneficios para con el hombre, es acusado de querer su mal. Adán y Eva tenían que elegir de quien fiarse, de su buenísimo Creador, o del acusador del cual no habían recibido ningún beneficio. Inexplicablemente rompieron la comunión con Dios por un acto radical de desconfianza, de sospecha hacia su santidad, de negación de su bondad. Aceptar la mentira de que Dios era malo rompió por dentro al hombre, corrompió su comunión con Él, secó la fuente de vida procedente de su confianza, y entró la muerte y el pecado.

16 Cf. Scott W. HAHN, "Canon, Culto y Alianza. La promesa de una hermenéutica litúrgica”, en Carlos Granados García - Agustín Giménez González (eds.), Biblia y ciencia de la fe (Religion. Ensayos 311), Madrid, Encuentro, 2007, 193.

17 Cf. Gérard-Henry BAUDRY, "A propos du péché originel, approches bibliques", EeV 105 (1995) 509; Giuseppe DE CARLO, "Il demonio artefice della caduta e il peccato dell'uomo. Il tentatore da Gen 3 a Sap 2,24", en G. BARTONe - G. BiguzZI (eds.), Angeli e demoni nella Bibbia (SBTA 18), Napoli, Edizioni Issra, 1998, 30. 
Esta ha sido siempre la gran mentira de Satán, que solo busca esto, que Dios —el infinitamente santo- sea maldito por su criatura. Aquí se esconde la raíz del pecado y, al mismo tiempo, el secreto del éxito del plan de Dios.

Recordemos al pueblo de Israel durante su marcha por el desierto. Su pecado continuo es acusar a Dios de querer su muerte, de ser malo. En vez de acoger que les ha liberado de la esclavitud de Egipto por amor y para llevarlos a una tierra maravillosa, le maldicen en todo momento:

- Frente al mar Rojo, porque dicen que les sacó para hacerles morir a manos de los egipcios o ahogados (cf. Éx 14,11-12). ${ }^{18}$

- $\quad$ En los diversos desiertos, porque les ha liberado para matarlos de sed o de hambre (cf. Ex 16,3; passim). ${ }^{19}$

- En Cades-Barnea, se niegan a entrar en la tierra prometida porque recriminan a Dios haberles tendido una trampa para morir a manos de sus habitantes (Núm 14,1-10). ${ }^{20}$

En vez de reconocer la santidad de Dios y pedir confiadamente su ayuda, pecan maldiciéndole y rebelándose.

Es lo mismo que pretende Satán con respecto a Job. Quiere que el más justo de los hombres maldiga a Dios para demostrarle a este que no es digno de ser amado de verdad por nadie; que solo logra que sus criaturas le amen por los regalos que les hace, pero que ninguno le ama por sí mismo. Dios, en un acto de confianza en la santidad de Job permite que sea probado terriblemente por Satán, que desea arrancar como sea una maldición de la boca de Job. ${ }^{21}$ Sin embargo, este muestra su santidad defendiendo la bondad de Dios: "El Señor me lo dio, el Señor me lo quitó; bendito sea el nombre del Señor [...]. Si aceptamos de Dios los bienes, ¿no vamos a aceptar los males?" (Job 1,21; 2,10).

Job, junto con otros santos del AT y tantos salmos que alaban a Dios por su inmensa bondad, vence al pecado bendiciendo a Dios. Sin embargo, estos son la excepción en la historia de la humanidad. La Biblia testimonia cómo desde los orígenes los hombres se fueron alejando cada vez más gravemente de Dios, hasta el punto de que el proyecto de la creación parece convertirse en un fracaso absoluto:"Al ver el Señor que la maldad del hombre crecía sobre la tierra y que todos los pensamientos de su corazón tienden siempre y únicamente al mal, el Señor se arrepintió de haber creado al hombre en la tierra y le pesó de corazón" (Gén 6,5-6).

18 Cf. Brevard S. ChiLds, El Libro del Éxodo. Comentario crítico y teológico (NBE.P), Estella, Verbo Divino, 2003, 251.

19 Cf. George W. Coats, Rebellion in the Wilderness. The murmuring motif in the Wilderness: traditions of the Old Testament, Nashville, Abingdon, 1968.

20 Cf. Pierre Buts, El libro de los Números (CuaBi 78), Estella, Verbo Divino, 1993, 12.

21 Cf. Agustín Giménez GonzÁlezz, “La persecución de Satán a Job (Job 1-2)”, en Manuel ArozteguI Esnaola (ed.), Palabra, Sacramento y Derecho. Homenaje al Cardenal Antonio $M^{a}$ Rouco Varela, Madrid, UESD - BAC, 2014, 360-369. 
Sin embargo, frente al aparente fracaso, Dios no va a reaccionar destruyendo a la humanidad, conforme a la conclusión del relato del diluvio en Gén 8,20-22. ${ }^{22}$ Su plan para lograr que el hombre viva su santidad será otro: elegirse un pueblo con el que hacer una alianza para, por su medio, llevar su bendición a todas las naciones (cf. Gén 12,1-3).

De hecho, la alianza que hará con Israel en el Sinaí tiene como consecuencia primera que Dios bajará a habitar con su pueblo, y su santidad será visible en forma de columna de nube por el día y columna de fuego por la noche. Dios quiere seguir intentando vivir en comunión con los hombres. Pero, para poder llevarlo a cabo, el pueblo debe ser purificado, santificarse, para poder estar tan cerca de la santidad de Dios y no ser consumido por esta (cf. Éx 19-23). De ahí la exigencia especial para Israel de cumplir la ley de santidad que Dios le entrega: la necesita para poder convivir con Dios.

No obstante, aparentemente, también este plan va a venirse abajo, pues el testimonio bíblico de la historia de este pueblo durante doce siglos es de infidelidad. Nada más realizar la alianza, la rompen estrepitosamente quebrantando el primero y más fundamental de los mandamientos, el de no hacerse ídolos ni postrarse ante ellos (cf. Éx 32: pecado del becerro de oro). ${ }^{23}$ Ya hemos mencionado las continuas maldiciones del desierto, y la negativa a entrar en la tierra prometida, por no hablar del terrible pecado de fornicación, adulterio e idolatría con las moabitas de Baal Peor, solo sofocado por el celo santo de Pinjás (cf. Núm 25). Podríamos seguir mencionando infidelidades en tiempos de los jueces, o los pecados de los reyes malos como Roboam, Jeroboam, Ajab, Manasés, Ocozías, Joaquín, Sedecías, etc., e incluso de los reyes buenos, como el adulterio-asesinato del rey David, o la idolatría final de Salomón.

Desde el libro del Génesis a 2 Reyes, desde los profetas del siglo viII hasta los del post-exilio, el AT testifica continuamente la historia de la no-santidad de Israel, salvándose solo honrosas excepciones. Ahora bien, estas le bastarán a Dios para que su plan siga adelante con éxito, pues su santidad es mayor que el pecado del hombre.

\section{EL MANDATO Y LA PROMESA}

En el corazón del Código de Santidad leemos: "Sed santos, porque yo, el Señor, vuestro Dios, soy santo" (Lv 19,2). ${ }^{24}$ Así traduce la actual versión litúrgica, acentuando el mandato y la exigencia de ser santos (pues el Dios Santísimo habita en medio de su pueblo), con el imperativo"sed santos".

22 Cf. Grelot, Hombre, ¿quién eres?, 50.

23 Cf. Claude Wiéner, El libro del Éxodo (CuaBib 54), Estella, Verbo Divino, 1986, 43-44.

24 Cf. James M. ArCADI, "YYou Shall Be Holy»: A Speech Act Theoretic Theological Interpretation", Journal of Theological Interpretation 12 (2018) 183-199. 
Sin embargo, ni la LXX ni la TaNaK emplean el imperativo, sino el futuro:

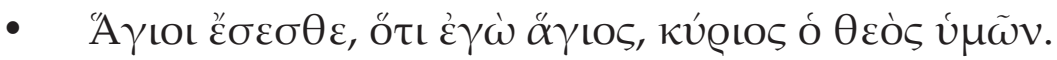

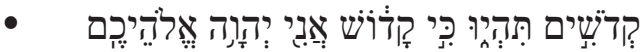

"Seréis santos -hagioi-, porque yo soy santo, el Señor, vuestro Dios". La traducción literal no solo mantiene el carácter exhortativo de la frase a ser santos, sino que añade el importantísimo matiz de promesa. Dios se compromete a hacerles santos en el futuro. Es como si les dijese: vosotros, que sois incapaces de ser santos por vosotros mismos (como demostrarán los siglos futuros de la historia de Israel), llegaréis a serlo por mi santidad, porque yo lo haré posible, porque os regalaré mi santidad.

Más adelante la promesa aparecerá en boca de los profetas, especialmente de Jeremías y Ezequiel. Así, en Jr 31,31-34 leemos: ${ }^{25}$

"Haré con la casa de Israel y la casa de Judá una alianza nueva. [...] Pondré mi ley en su interior y la escribiré en sus corazones; yo seré su Dios y ellos serán mi pueblo. Ya no tendrán que enseñarse unos a otros diciendo: "Conoced al Señor», pues todos me conocerán, desde el más pequeño al mayor —oráculo del Señor-, cuando perdone su culpa y no recuerde ya sus pecados".

Por su parte, Ez 36,24-28:26

"Derramaré sobre vosotros un agua pura que os purificará: de todas vuestras inmundicias e idolatrías os he de purificar; y os daré un corazón nuevo, y os infundiré un espíritu nuevo; arrancaré de vuestra carne el corazón de piedra, y os daré un corazón de carne. Os infundiré mi espíritu, y haré que caminéis según mis preceptos, y que guardéis y cumpláis mis mandatos".

Como puede verse, ambos profetas anuncian una acción futura de Dios por la que este transformará al hombre en una criatura nueva. Lo hará desde dentro, en el interior del hombre, por obra de su espíritu de santidad. El resultado será un pueblo santo y fiel al amor de Dios, que viva en comunión e intimidad con él.

Esta no es otra que la obra redentora, justificadora, salvadora y santificadora de nuestro Señor Jesucristo en el misterio pascual y envío del Espíritu Santo, todo lo cual aparece abundantemente testimoniado en el NT. Como señala Pedro en el discurso de Pentecostés, todo lo que uno debe hacer es creer en el Señor Jesús, muerto y resucitado, y ser bautizado en su nombre, recibiendo

25 Cf. Jacques Briend, El libro de Jeremías (CuaBib 40), Estella, Verbo Divino, 1983, 43-47; Luis Alonso SchöKel - José Luis Sicre Díaz, Profetas I. Isaías - Jeremías (NBE), Madrid, Cristiandad, 1980, 551-575.

26 Cf. José María Asurmendi, Ezequiel (CuaBi 38) Estella, Verbo Divino, 1982, 51-53; Carlos GranaDOs García, La nueva alianza como recreación. Estudio exegético de Ez 36,16-38 (Analecta biblica 184), Roma, Gregorian \& Biblical Press, 2010. 
así el perdón de los pecados y la plenitud del Espíritu Santo anunciado por los profetas (cf. Hch 2,37-39: "Preguntaron a Pedro y a los demás apóstoles: ¿Qué tenemos que hacer, hermanos? Pedro les contestó: Convertíos y sea bautizado cada uno de vosotros en el nombre de Jesús, el Mesías, para perdón de vuestros pecados, y recibiréis el don del Espíritu Santo. Porque la promesa vale para vosotros y para vuestros hijos"). ${ }^{27}$

La recepción del Bautismo incluía en los primeros siglos de la Iglesia, como culmen del rito, la participación en la Eucaristía, esto es, en la alianza nueva y eterna (cf. Lc 22,20). La Eucaristía, como se sigue de los relatos sinópticos de su institución, y de las cartas de Pablo, supone la participación en el misterio de la pasión, muerte y resurrección de Cristo, el acontecimiento salvífico de la humanidad. En esa última cena, Jesús se identificó con el siervo del cuarto cántico de Isaías, al señalar que el cáliz era su sangre derramada "por muchos" para el perdón de los pecados (cf. Mt 20,28; Mc 14,24), pues también el siervo es víctima de expiación "por muchos" (cf. Is 53,11: "Mi siervo justificará a muchos, porque cargó con los crímenes de ellos"). ${ }^{28}$

Ahora bien, dicha Eucaristía no sólo redime al que la recibe, sino que le santifica y le llena de vida, pues es el verdadero pan que ha bajado del cielo, que otorga la vida eterna y la comunión plena con el Hijo eterno del Padre (cf. Jn 6; 1 Cor 11,23-27). ${ }^{29}$ En efecto, al comulgar con amor, el cristiano come al Santísimo que, entrando en el interior del hombre, lo transforma, lo hace una criatura nueva, escribe en su corazón la ley de santidad y lo introduce en la comunión con el Padre y el Hijo en el Espíritu. Así, el cristiano se transforma en lo que come, como diría san Agustín, haciéndose cuerpo de Cristo y viviendo su santidad por el espíritu de filiación divina que ha recibido. Al hombre le toca corresponder a tan magnífico don acogiéndolo con gratitud y proclamando ante el mundo entero: "Dios es infinitamente bueno, y nos ha mostrado su amor eterno entregándonos a su Hijo".

Por otra parte, la manifestación más clara de que uno ha sido transformado por Dios es una vida santa. Por eso la vocación de los cristianos es reflejar la santidad de Dios en su vida, posible solo gracias a la acción del mismo Dios, pues como decía san Pablo: "No soy yo el que vive, es Cristo quien vive en mí" (Gal 2,20). ${ }^{30}$ Así, Jesús insiste a sus discípulos que deben amar como Dios ama, para ser verdaderamente hijos de Dios. ${ }^{31}$ Deben amar a sus enemigos porque

27 Cf. Alfred Wikenhauser, Los Hechos de los Apóstoles (BH.SE 96) Barcelona, Herder, 1973, 57-86.

28 Cf. Sydney H. T. PAGE, "The Suffering Servant between the Testaments”, NTS 31 (1985) 481-497.

29 Cf. Eugene Walter, Primera Carta a los Corintios (El Nuevo Testamento y su mensaje 7) Barcelona, Herder, 1977, 205-215.

30 Cf. Heinrich Schlier, La carta a los Gálatas (BEB 4) Salamanca, Sígueme, ²1999, 120-122.

31 Cf. Matthew Vellanickal, The Divine Sonship of Christians in the Johannine Writings (AnBib 72), Rome, Biblical Institute Press, 1977, 56-61; Agustín GiménEz GonZÁLEz, "Si el justo es Hijo de Dios, le socorrerá" (Sab 2,18). Acercamiento canónico a la filiación divina del justo perseguido en Sab 1-6 (ABE 48), Estella, Verbo Divino, 2009, 363-365. 
Dios ama a todos, y si lo hacen, llegarán a ser hijos de Dios (cf. Mt 5,43-48). Ahora bien, Jesús muestra con su propia vida cuál es el camino de la santidad: él mismo. Por eso Pablo invita a los filipenses a adoptar los mismos sentimientos de Cristo Jesús, entre los que sobresalen la comunión con los demás y la humildad. ${ }^{32}$

No obstante, la obra santificadora de Dios en el hombre no concluye con la recepción del Espíritu Santo en el seno de la Iglesia, y la transformación de la propia existencia en una vida de santidad. Esta acción solo llegará a su plenitud en los cielos nuevos y la tierra nueva, con la resurrección final en la que seremos revestidos de la resurrección gloriosa de Cristo y todo nuestro ser, cuerpo y alma, será transido por la santidad de Dios (cf. Rm 8,17-19). ${ }^{33}$

Mientras llega ese momento, caminemos en la santidad de Cristo, por el Espíritu, de la mano de María Santísima, la kecharitomene, la plenamente llena de gracia (cf. Lc 1,28), la criatura donde se refleja de modo perfecto la santidad de Dios.

32 Cf. Agustín Grménez GonzÁLez, "Por la comunión y humildad a la divinidad y filiación (Flp 2,518)", Reseña Bíblica 53 (2007) 29-38.

33 José María Bover, Teología de San Pablo. El misterio de Cristo contemplado por el Apóstol (BAC 16) Madrid, BAC, ${ }^{3} 1961,813-816$. 